\title{
EDITORIAL
}

\section{Is there still a place for the Swan-Ganz catheter? Yes}

\author{
Julien Demiselle ${ }^{1,2}$, Alain Mercat ${ }^{1,2}$ and Pierre Asfar ${ }^{1,2^{*}}$
}

(C) 2018 Springer-Verlag GmbH Germany, part of Springer Nature and ESICM

Swan-Ganz catheter use in the intensive care unit (ICU) is an endless matter of debate.

In the past decade echocardiography has emerged as a major tool for understanding mechanisms of shock. We do not deny the utmost importance of echocardiography in the early phase of management of patients with shock. However, the use of echocardiography as a monitoring device is highly time consuming and operator dependent. For these reasons, we exclude echocardiography from this pro/con debate.

As experts have no clear-cut opinion between SwanGanz catheter versus transpulmonary thermodilution for the diagnosis and monitoring of patients with shock states, we will review and defend Swan-Ganz catheter advantages.

Modern hemodynamics approach in ICU relies on theoretical concepts that have been validated through heart catheterization. The Swan-Ganz catheter was the first device to make possible the application of heart catheterization at the bedside [1] and allowed us to build our common knowledge of systemic, as well as pulmonary hemodynamics. For these historical reasons, Swan-Ganz catheters represent a key pedagogical tool for teaching, learning and understanding hemodynamics and shock pathophysiology [2]. Moreover, in patients with acute respiratory distress syndrome (ARDS), it provides meaningful information for correct interpretation of gas exchange [3].

Swan-Ganz catheter provides measurements of right and left ventricular preloads by the direct measurement of pressures (central venous pressure, right atrial pressure, pulmonary artery pressure and pulmonary artery occlusion pressure), as well as cardiac output (using thermodilution principle, a robust technique) and mixed venous oxyhemoglobin saturation (SvO2). The SwanGanz catheter allows calculation of important metabolic variables such as oxygen delivery, consumption and extraction. Furthermore, it allows estimation of vasomotor tone through pulmonary and systemic vascular resistance indexes.

The most recent version of Swan-Ganz catheters with continuous cardiac output and $\mathrm{SvO} 2$ monitoring are especially appreciated in patients with low cardiac output. Of note, Swan-Ganz catheters without these automatic and continuous monitoring options are less adequate for early warning.

Despite the development of other monitoring tools in the ICU, the Swan-Ganz catheter is the only device offering the possibility to assess easily and monitor continuously right ventricle function [4]. This is helpful to diagnose right ventricle failure in everyday life, which is reflected by increased right atrial pressure and decreased 


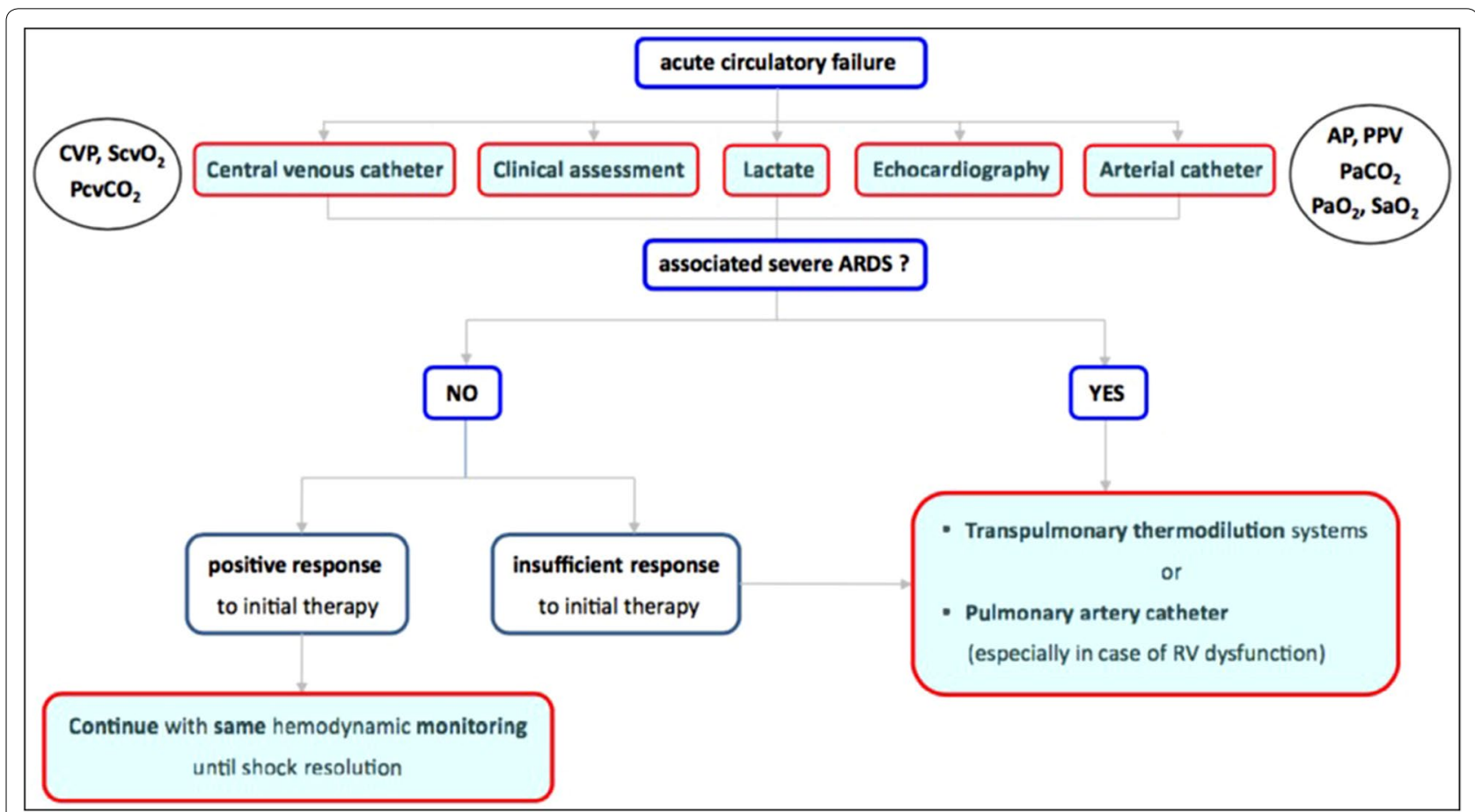

Fig. 1 Simplified algorithm for the choice of hemodynamic monitoring in patients with acute circulatory failure, in Intensive Care Med (2016) 42:1350-1359. AP arterial pressure, ARDS acute respiratory distress syndrome, CVP central venous pressure, PaCO2 carbon dioxide pressure in the arterial blood, $\mathrm{PaO} 2$ oxygen pressure in the arterial blood, $\mathrm{P}$ cVCO2 carbon dioxide pressure in the central venous blood, $P P V$ pulse pressure variation, $\mathrm{RV}$ right ventricular, $\mathrm{SaO} 2$ arterial blood oxygen saturation, $\mathrm{ScvO} 2$ central venous blood oxygen saturation

pulmonary artery pressure, especially in ARDS patients and or in patients with septic shock, both at high risk of right ventricular failure. In addition, and to the best of our knowledge, this is the only tool that allows deciphering between pre- and post-capillary pulmonary hypertension. In the context of personalized ventilatory strategies in ARDS [5], it allows rapid assessment of ventilator setting's impact on right ventricular function. In situations at risk of right ventricular failure, conversely to transpulmonary thermodilution technique, the Swan-Ganz catheter remains the best friend of the intensivist.

We do not deny that the Swan-Ganz catheter does not allow dynamic measures and, therefore, is not adequate to predict fluid responsiveness. In appeased debate, it is important to target the final goal of a fluid challenge. Is it to increase stroke volume, per se, or to increase oxygen delivery in fluid responsive patients? Except in very hypovolemic patients a fluid challenge increases transiently [6] stroke volume especially in patients with circulatory shock, but due to hemodilution, oxygen delivery increases inconstantly [7]. Finally, should we throw away static hemodynamic measures? In our opinion certainly not! Indeed, monitoring of static hemodynamic measurements limit excessive and inappropriate treatments such as excessive fluid infusion or inotrope administration.
The clinical impact of Swan-Ganz catheter use in critically ill patients has been questioned by Connors et al. [8]. However, several large randomized controlled trials clearly demonstrated that the use of the Swan-Ganz catheter do not, per se, increase mortality [9-11]. Interestingly, the Swan-Ganz catheter is the only hemodynamic monitoring tool for which we have a so high a level of evidence of safety.

Currently, recommendations state that invasive monitoring must be restricted for the most severe patients and complex clinical situations, such as patients with refractory shock with or without acute respiratory distress syndrome $[12,13]$. In these settings, according to the most recent recommendations of the European Society of Intensive Care Medicine and a panel of clinicians led by Teboul $[12,14]$, it has been suggested to use an invasive monitoring device such as a Swan-Ganz catheter or transpulmonary thermodilution systems.

Pragmatically, how do we decide between these two continuous monitoring devices? From our point of view, the four following points should be considered before insertion of an invasive monitoring tool: the clinical question, the invasiveness, safety and cost of the device.

To answer this clinical question, the panel of experts directed by Teboul proposed an algorithm presented in 
Fig. 1 [14]. Both monitoring devices are proposed with a special emphasis for the Swan-Ganz catheter in the situation of right ventricular failure. The use of transpulmonary thermodilution is suggested in patients with acute respiratory distress syndrome to improve fluid management with the estimation of extravascular lung water. Of note, these good sense suggestions were not validated by evidence based medicine proofs.

Regarding the invasiveness and safety of both devices, the intensivist must choose between the placement of a simple radial arterial line with a Swan-Ganz catheter and the placement of a larger arterial catheter with a multi-lumen jugular venous catheter for transpulmonary thermodilution. With hindsight, in our opinion and for a similar invasive approach, we finally have robust data regarding the safety of the Swan-Ganz catheter that are lacking for transpulmonary thermodilution systems.

To date, the issue of the cost of such devices is an unknown factor: cost varies across hospitals, and cost effectiveness between these devices has not been compared yet.

Challengers of the Swan-Ganz catheter argue that adequate measurements and interpretation of hemodynamic data requires expertise. We do not deny that a learning program and training is mandatory for adequate use of the Swan-Ganz catheter and to achieve relevant hemodynamic targets that may improve a patient's outcome [15]. This should not be an argument against the SwanGanz monitoring use as this statement is also true for other, more or less invasive, tools.

In summary, Swan-Ganz has still a full place in the ICU for the more severely ill patients and has proven across years its reliability and safety. The Swan-Ganz catheter must be preserved and taught properly to remain a key tool for bedside hemodynamic monitoring.

\footnotetext{
Author details

${ }^{1}$ Département de Réanimation Médicale et de Médecine Hyperbare, Centre Hospitalier Universitaire, 4, Rue Larrey, 49933 Angers Cedex 9, France. ${ }^{2}$ LUNAM
} Université, Université d'Angers, Angers, France.

\section{Compliance with ethical standards}

\section{Conflicts of interest}

None of the authors has a conflict of interest related to this manuscript.
Received: 16 February 2018 Accepted: 28 March 2018

Published online: 23 May 2018

\section{References}

1. Swan HJ, Ganz W, Forrester J et al (1970) Catheterization of the heart in man with use of a flow-directed balloon-tipped catheter. N Engl J Med 283:447-451. https://doi.org/10.1056/NEJM197008272830902

2. Sharkey SW (1987) Beyond the wedge: clinical physiology and the SwanGanz catheter. Am J Med 83:111-122

3. Radermacher P, Maggiore SM, Mercat A (2017) Fifty years of research in ARDS. Gas exchange in acute respiratory distress syndrome. Am J Respir Crit Care Med 196:964-984. https://doi.org/10.1164/rccm.201610-2156SO

4. Ventetuolo CE, Klinger JR (2014) Management of acute right ventricular failure in the intensive care unit. Ann Am Thorac Soc 11:811-822. https:// doi.org/10.1513/AnnalsATS.201312-446FR

5. Mercat A, Richard J-CM, Vielle B et al (2008) Positive end-expiratory pressure setting in adults with acute lung injury and acute respiratory distress syndrome: a randomized controlled trial. JAMA 299:646-655. https://doi. org/10.1001/jama.299.6.646

6. Nunes TSO, Ladeira RT, Bafi AT et al (2014) Duration of hemodynamic effects of crystalloids in patients with circulatory shock after initial resuscitation. Ann Intensive Care 4:25. https://doi.org/10.1186/s1361 3-014-0025-9

7. Asfar P, Kerkeni N, Labadie F et al (2000) Assessment of hemodynamic and gastric mucosal acidosis with modified fluid versus $6 \%$ hydroxyethyl starch: a prospective, randomized study. Intensive Care Med 26:1282-1287

8. Connors AF, SperoffT, Dawson NV, SUPPORT Investigators et al (1996) The effectiveness of right heart catheterization in the initial care of critically ill patients. JAMA 276:889-897

9. Richard C, Warszawski J, Anguel N et al (2003) Early use of the pulmonary artery catheter and outcomes in patients with shock and acute respiratory distress syndrome: a randomized controlled trial. JAMA 290:27132720. https://doi.org/10.1001/jama.290.20.2713

10. Rhodes A, Cusack RJ, Newman PJ et al (2002) A randomised, controlled trial of the pulmonary artery catheter in critically ill patients. Intensive Care Med 28:256-264. https://doi.org/10.1007/s00134-002-1206-9

11. Harvey S, Harrison DA, Singer M et al (2005) Assessment of the clinical effectiveness of pulmonary artery catheters in management of patients in intensive care (PAC-Man): a randomised controlled trial. Lancet Lond Engl 366:472-477. https://doi.org/10.1016/S0140-6736(05)67061-4

12. Cecconi M, De Backer D, Antonelli M et al (2014) Consensus on circulatory shock and hemodynamic monitoring. Task force of the European Society of Intensive Care Medicine. Intensive Care Med 40:1795-1815. https://doi.org/10.1007/s00134-014-3525-z

13. Rhodes A, Evans LE, Alhazzani W et al (2017) Surviving sepsis campaign international guidelines for management of sepsis and septic shock: 2016. Intensive Care Med 43:304-377. https://doi.org/10.1007/s0013 4-017-4683-6

14. Teboul J-L, Saugel B, Cecconi M et al (2016) Less invasive hemodynamic monitoring in critically ill patients. Intensive Care Med 42:1350-1359. https://doi.org/10.1007/s00134-016-4375-7

15. Gnaegi A, Feihl F, Perret C (1997) Intensive care physicians' insufficient knowledge of right-heart catheterization at the bedside: time to act? Crit Care Med 25:213-220 